\title{
Badanie możliwości monitorowania stanu technicznego rurociągów podziemnych z wykorzystaniem emisji akustycznej
}

\author{
Evaluation of acoustic emission utility for monitoring \\ the technological conditions of underground pipelines
}

\section{Streszczenie}

Badania nieniszczące (NDT) są istotnym elementem diagnozowania bezpiecznej eksploatacji rurociągów podziemnych. W przypadku nowych rurociągów o dużych średnicach badania NDT są prowadzone przy użyciu tzw. tłoków inteligentnych, których zastosowanie jest nie zawsze możliwe. W tym kontekście przedstawiono wyniki badań nad wykorzystaniem emisji akustycznej (AT) do monitorowania wad $w$ rurociągach podziemnych. Badania AT prowadzone $w$ warunkach laboratoryjnych miały na celu opracowanie metodyki pomiarowej, która miałaby zastosowanie w rzeczywistych warunkach eksploatacyjnych. Uzyskane wyniki potwierdziły możliwości AT w lokalizowaniu i monitorowaniu defektów powstających w podziemnych rurociągach. W ramach pracy wykonan również badania na rurociągach w rzeczywistych warunkach eksploatacyjnych. W wyniku tych badań powstały wytyczne do stworzenia systemu badawczego do detekcji i lokalizacji nieciągłości w przemysłowych podziemnych rurociągach przesyłowych.

\section{Abstract}

Non destructive testing (NDT) is of significant importance when it comes to safety evaluation of underground pipeline exploatation. In addition to regular NDT, an intelligent piston is used in a case of great diameter pipelines, although its usage is not always possible. In this respect, the results from monitoring underground pipeline defects with Acoustic Emission testing (AE) were presented. AE laboratory research was carried out to develop a methodology of measurements that could be applied in the real technological conditions. The obtained results prove the utility of $A E$ testing in localizing and monitoring defects in underground pipelines. A part of a research was carried out in real technological conditions. As a result, new guidelines were set up for scientific researches on detection and localization of material defects in underground pipelines under technological conditions.

\section{Metodyka badań}

Badania laboratoryjne AT zostały wykonane z wykorzystaniem modelowego rurociągu przedstawionego na rysunku 1.

Konstrukcja rurociągu pozwoliła na przeprowadzenie badań podczas kontrolowanych zmian ciśnienia

Dr inż. Krystian Paradowski, dr inż. Andrzej Zagórski, dr inż. Jan Płowiec, inż. Michał Bardadyn - Politechnika Warszawska. oraz przepływu cieczy i powietrza. Dodatkowo rurociąg miał możliwość zamontowania wycinków zawierających sztuczne wady materiałowe symulujące nieszczelność. Pozwoliło to na opracowanie metodyki lokalizacji sygnałów AE generowanych przez sztuczną wadę. Podczas badań wykonano również pomiary z wykorzystaniem czujnika akustycznego umieszczonego wewnątrz rurociągu, który umieszczony był na specjalnym module transportowym. Badania przemysłowe koncentrowały się na pomiarach $A E$ rurociągów w rzeczywistych warunkach eksploatacyjnych [1]. 


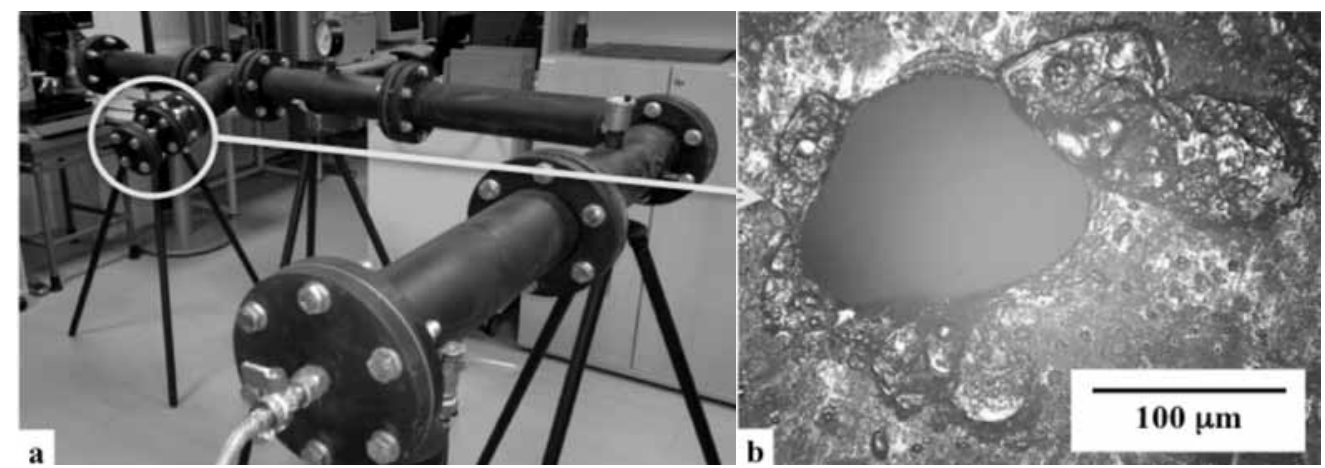

Rys. 1. Stanowisko do badań; a) modelowy rurociąg, b) sztuczna wada symulująca nieszczelność Fig. 1. Test stand: a) model pipeline, b) artificial defect simulating leak
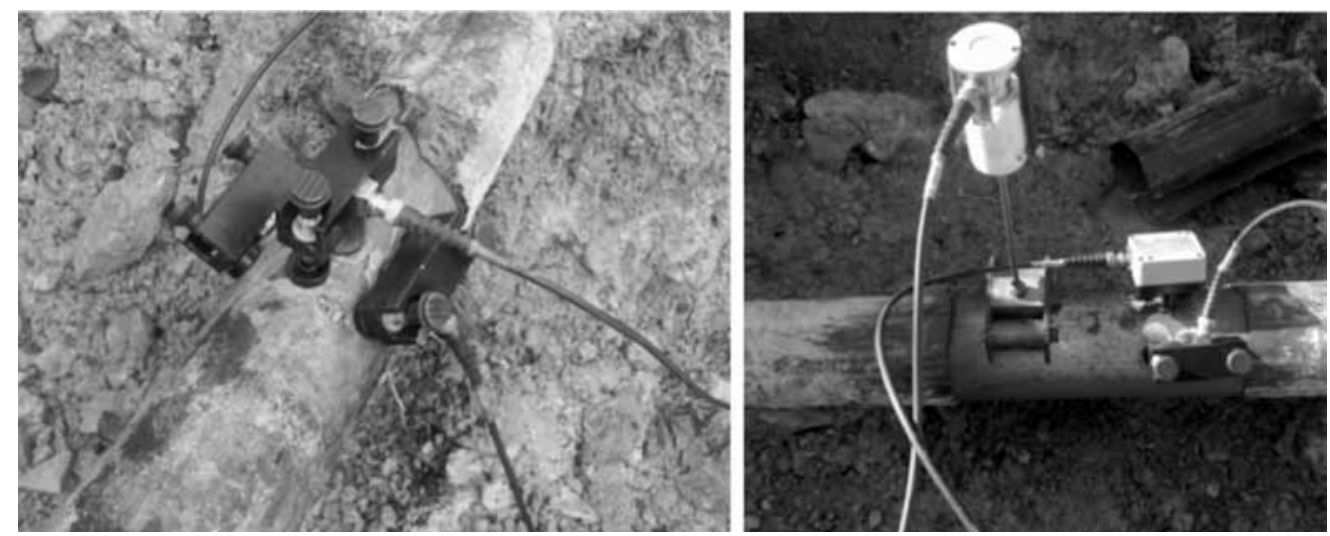

Rys. 2. Czujniki $A E$ zamontowane na badanym rurociągu

Fig. 2. AE sensors mounted on the pipeline

W pracy wykonano badania na $600 \mathrm{~m}$ eksploatowanego, podziemnego odcinka rurociągu gazu ziemnego podczas jego normalnej pracy oraz $\mathrm{w}$ trakcie zwiększania ciśnienia. Pomiar sygnałów AE realizowany był przy użyciu różnych czujników akustycznych o innych pasmach przenoszenia i czułości, montowanych bezpośrednio na rurociagu jak również z wykorzystaniem falowodów. Na rysunku 2 przedstawiono zdjęcie zamontowanych czujników AE na badanym rurociągu. W badaniach wykorzystano urządzenie do pomiarów metodą AT firmy Vallen z Niemiec. Wyniki pomiarów były przesyłane $z$ systemu pomiarowego $A E$ do operatora za pomocą modułu telemetrycznego. Zastosowanie takiego rozwiązania umożliwiło alarmowe powiadomienia drogą bezprzewodową o wynikach prowadzonych badań.

\section{Wyniki badań}

Analiza sygnałów AE pochodzących od sztucznego źródła stała się podstawą porównania sygnałów akustycznych generowanych przez wyciek powietrza i wody (rys. 3).

Podczas analizy porównano sygnały zarejestrowane podczas wycieku powietrza z wcześniej zarejestrowanymi sygnałami dla wycieku wody. Porównanie wykazało, że można zaprogramować system pomiarowy tak, żeby informował o rodzaju wyciekajacego medium. Dodatkowo potwierdzono, że istnieje możliwość zlokalizowania nieszczelności. Wyniki analizy przedstawiono na rysunku 4. Badania wykazały, że znaczący wpływ na lokalizację sygnałów AE ma rodzaj medium wypełniającego rurociąg.

Badania przemysłowe wykazały że też metodą AT można monitorować podziemne rurociągi przesyłowe. Przykładową lokalizację liniową przedstawiono na rysunku 5.

Podczas badania AT podziemnych rurociągów mogą być stosowane czujniki $A E$ zamontowane na falowodach. Przy tym zastosowaniu falowody stanowią część pośrednią umożliwiającą kontakt czujnika z powierzchnią badanego obiektu. W przypadku rurociągów o małej średnicy falowody polepszają kontakt czujnika z powierzchnią. Jest to szczególnie istotne, gdy wykop w miejscu zamontowania czujników jest narażony na zalanie wodą. Falowody można również zamontować na stałe do rurociągu, co umożliwia prowadzenie długotrwałych pomiarów. Badania AT umożliwiły na określenie odległości między poszczególnymi czujnikami montowanymi na rurociągu, który wypełniony jest gazem. Dla czujników AE o pasmie przenoszenia w zakresie niskich częstotliwości odległość ta powinna wynosić ok. $50 \mathrm{~m}$. W trakcie badania należy pamiętać o wyłączeniu ochrony katodowej. Ponadto trzeba zwrócić uwagę na prądy błądzące, powodujące wzrost zakłóceń. 


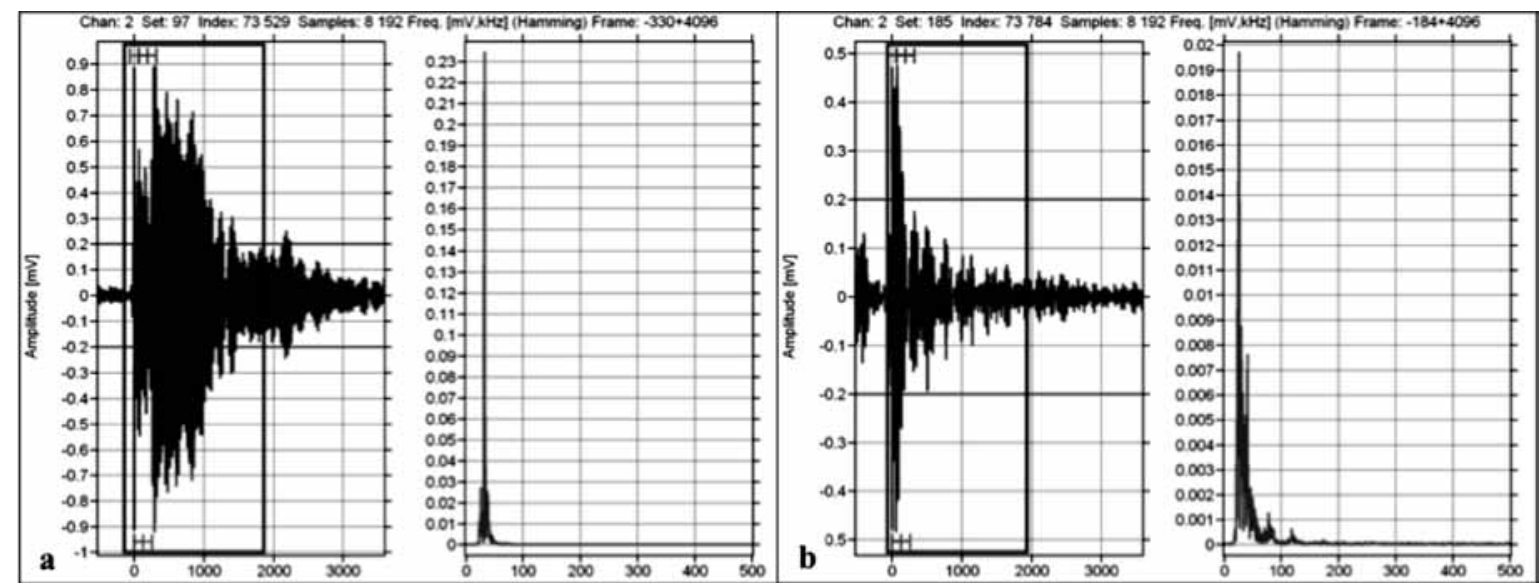

Rys. 3. Przykładowy kształt fali akustycznej oraz częstotliwość sygnałów dla wody (a) i powietrza (b)

Fig. 3. An example of a waveform and frequency of the acoustic signals for water (a) and air (b)
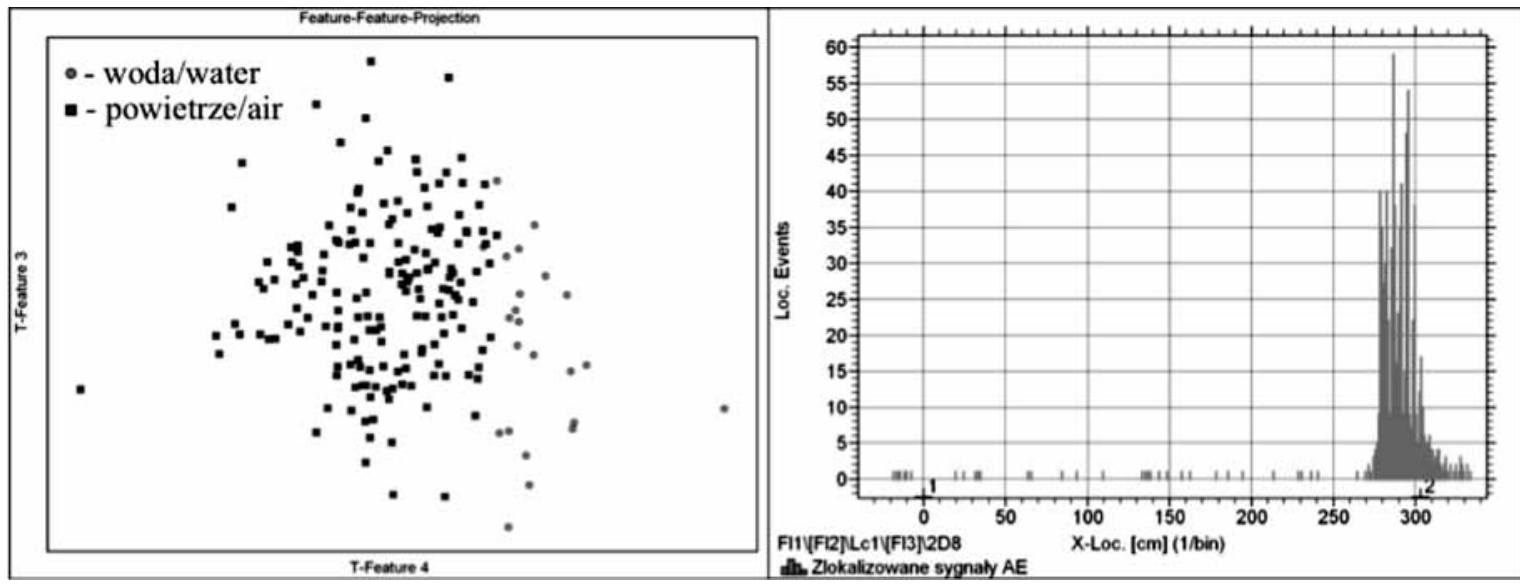

Rys. 4. Klasyfikacja sygnałów $A E$ generowanych $z$ wycieku wody i powietrza z lokalizacją liniową

Fig. 4. The classification of $A E$ linear location signals identified as air and water leakage

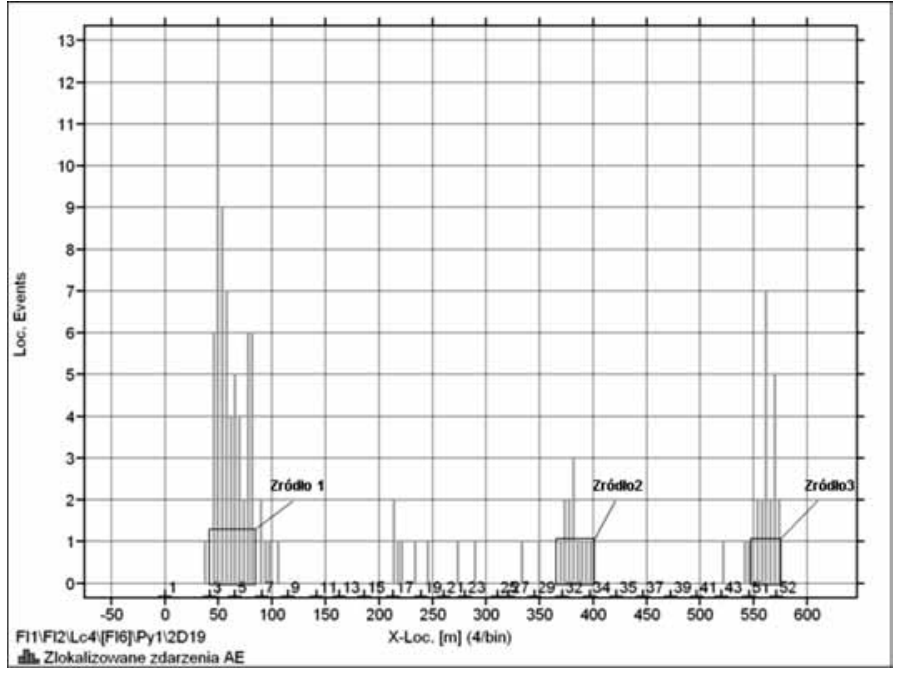

Rys. 5. Lokalizacja liniowa zdarzeń AE wykrytych na $600 \mathrm{~m}$ odcinku rurociągu podziemnego

Fig. 5. Linear location of AE events detected on a $600 \mathrm{~m}$ section of underground pipeline 


\section{Podsumowanie}

Badania wykazały, że możliwe jest zastosowanie metody AT do monitorowania stanu technicznego rurociągów podziemnych. Głównym ograniczeniem tej metody badania są zakłócenia sygnałów akustycznych wynikające z przepływu cieczy oraz pochodzące od prądów błądzących [2]. W przypadku czujników AE o niskiej częstotliwości, zamontowanych na rurociągu wypełnionym gazem, odległość pomiędzy czujnikami powinna wynosić ok. $50 \mathrm{~m}$. Dla rurociągów wypełnionych cieczą odległość ta może być większa. Testy laboratoryjne wykazały, że możliwe jest wykrywanie nieszczelności przez czujniki umieszczone wewnątrz rurociągu. Możliwe jest rozróżnienie sygnałów $A E$ od wycieku powietrza i cieczy. Należy zaznaczyć, że skuteczność pomiarów AT zależy od materiału, z jakiego wykonano rurociąg, rodzaju transportowanego medium oraz parametrów eksploatacji, takich jak prędkość przepływu i ciśnienie [3, 4]. W wyniku przeprowadzonych prac powstały procedury i instrukcje badań AT podziemnych rurociągów przesyłowych.

\section{Literatura}

[1] Paradowski K., Spychalski W. L., Ciesielski M., Zagorski A.,Kurzydlowski K. J., "Acoustic Emission for Industrial Applications", Technical Workshop VI - Operation of High-Pressure Pipelines in The Aspect of The UDT and The EU", 2005.

[2] Skalskyi V., Koval P.: Some Methological Aspects of Application of Acoustic Emission, Lviv, 2007.
[3] Miller R. K., Pollock A. A., Watts D.J., Carlyle M. J., Tafuri A. N., Yezzi Jr J. J.: A Reference Standard for The Development of Acoustic Emission Pipeline Leak Detection Techniques, NDE\&E International 32, 1999, s. 1-8.

[4] Bilman L., Isermann R.; Leak Detection Methods for Pipeline, Automatica, vol.23, 3/1987, s. 381-385.

\section{Podziękowanie}

\section{Diagnostyka drganiowa turbozespołu. Studium przypadku}

\section{Vibration diagnostics of the turbine. A case study}

W artykule przedstawiono strategie nadzorowania oraz zaprezentowano studium przypadku. Ponieważ nadzór dotyczył turbozespołu, czyli newralgicznego urządzenia bloku zastosowano nadzór specjalistyczny. Pokazano, że dla prawidłowej diagnostyki konieczne jest uwzględnianie wielu parametrów i ich korelowanie: obserwacja wyłącznie poziomów drgań nie pozwoliłaby na poprawną diagnozę. Korelacja sygnałów drganiowych oraz parametrów technologicznych turbozespołu pozwoliła w prawidłowy sposób zaproponować remont, zaplanować czas postoju oraz wstępnie oszacować koszty remontu.
The paper presents monitoring strategies and a monitoring case study. Since the turbine was monitored a specialized strategy was applied. It was shown that an efficient diagnostics requires considering multiple parameters and their correlation: observation of only vibration levels is not sufficient for a correct diagnosis. Correlation of vibration signals and technological parameters of the turbine allowed to propose the repair, plan the downtime and estimate the costs of the repair.

Referat wygłoszono podczas 42. KKBN w Kołobrzegu 